\title{
AUTOAVALIAÇÃO E AVALIAÇÃO POR PARES DE COMPETÊNCIAS TRANSVERSAIS DE ESTUDANTES DE ENGENHARIA: ESTUDO PILOTO
}

\author{
DOI: 10.37702/2175-957X.COBENGE.2021.3422
}

Tatiana Gesteira de Almeida Ferraz - tatianaa@fieb.org.br

Centro Universitário SENAI CIMATEC

Av.Orlando Gomes 1845

41650-010 - Salvador - BA

CAMILA DE SOUSA PEREIRA GUIZZO - camila.pereira@fieb.org.br

SENAI CIMATEC

AV ORLANDO GOMES 1845

41650-010 - SALVADOR - BA

Renelson Ribeiro Sampaio - renelson.sampa@gmail.com

Centro Universitário SENAI CIMATEC

Av. Orlando Gomes 1945

41650-010 - Salvador - BA

Resumo: As mudanças recentes no perfil de saída previsto para os estudantes de engenharia visando atender às transformações da sociedade contemporânea, traz aos professores e às instituições de ensino superior o desafio não só de formar, como também de avaliar as competências transversais dos estudantes. A avaliação destas competências é um processo complexo, ainda não muito estudado por pesquisadores, carecendo-se, portanto, do desenvolvimento de ferramentas adequadas. Este trabalho discute os resultados parciais de um estudo de doutorado. $O$ objetivo deste artigo é apresentar o processo de desenvolvimento e os testes iniciais de um instrumento para autoavaliação e avaliação por pares de competências transversais de estudantes de engenharia. Os resultados preliminares indicam que o modelo proposto se mostrou adequado, sendo possível envolver os estudantes na avaliação das competências transversais. Não se percebeu diferenças significativas entre as medianas das autoavaliações e avaliações pelos pares. Na sequência da pesquisa, está previsto o refinamento dos itens do instrumento e a aplicação da avaliação com maior número de estudantes, além de professores e agentes externos. Acredita-se que, ao explicitar as 
competências transversais e avaliar o grau de desenvolvimento destas competências, favorece-se o reconhecimento dos gaps e a busca pela melhoria contínua, não só por parte dos próprios estudantes, como também pelos professores e instituições de ensino.

Palavras-chave: Educação em engenharia. Competências transversais. Avaliação de estudantes. Autoavaliação. Avaliação por pares. 


\section{INTRODUÇÃO}

O desenvolvimento tecnológico aliado às rápidas transformações no mundo trouxe às instituições de ensino de engenharia o desafio de aliar a transmissão de um crescente conhecimento técnico à necessidade de formar profissionais com as competências necessárias para desenvolver produtos, processos e sistemas de engenharia cada vez mais complexos (CRAWLEY et al., 2014). Neste sentido, amplia-se o escopo de atuação das universidades, que passam a ter que desenvolver não só as competências técnicas específicas, como também as competências transversais para que os egressos dos cursos de engenharia desempenhem o papel esperado pela sociedade. Com isso, apresenta-se aos professores e às instituições de ensino superior (IES) o desafio não só de formar, como também de avaliar o desenvolvimento das competências transversais dos estudantes.

As competências complementares às competências técnicas específicas recebem diversas denominações na literatura: gerais, genéricas, transversais, chave, soft skills (MORGA, CUSÓ, JUÁREZ, 2018) e são estudadas por pesquisadores de diferentes áreas do conhecimento (administração, pedagogia e psicologia) (FLEURY e FLEURY, 2001). O conceito de competência transversal refere-se à capacidade de transferir e aplicar conhecimentos e habilidades em diferentes contextos da sociedade (BRIDGES, 1993; ROCHA, 2015). É também associado, conforme conceituado no Projeto Tuning (GONZÁLEZ; WAGENAAR, 2003), e adotado por diversos autores (YE-LIN et al., 2019; CLARES; MORGA, 2019; MORGA; CUSÓ; JUÁREZ, 2018; AGUADO et al., 2016) ao conjunto de conhecimentos, habilidades, atitudes e valores, de caráter genérico, necessários aos egressos de quaisquer cursos superiores, que servem de base ao desenvolvimento das demais competências.

Moreno (2006), por sua vez, distingue as competências transversais das competências básicas e técnico-profissionais, descrevendo-as como aquelas que possibilitam ao profissional "adquirir mais facilmente novas competências, adaptar-se às novas tecnologias e aos novos contextos organizacionais, ter mobilidade no mercado de trabalho e desenvolver sua própria carreira" Moreno (2006, p.37). Apesar de haver algumas diferenças entre as definições adotadas pelos diversos autores, observa-se que, na essência, as competências transversais são complementares às competências técnicas específicas e referem-se à capacidade de desenvolver novas competências e adaptar conhecimentos, habilidades a atitudes a diferentes contextos, visando a solução de problemas reais, num mercado de trabalho dinâmico.

A avaliação de competências transversais de estudantes de engenharia é um processo complexo, ainda não muito estudado por pesquisadores, carecendo-se, portanto, do desenvolvimento de ferramentas adequadas para esta finalidade (BALDERAS et al., 2018; GILL; RITZHAUPT; 2013; ADRIAENSEN, BIJSMANS, GROEN, 2019; YE-LIN et al., 2019; CLARES e MORGA, 2018). Na revisão de literatura realizada contemplando artigos publicados em inglês, português ou espanhol, de 2010 a 2020, disponíveis nas bases Scopus e Web of Science, observou-se que a maioria dos estudos e instrumentos utilizados para avaliação de competências transversais dos estudantes têm um caráter específico, tendo sido desenvolvido e aplicado para um determinado método de ensino, curso ou disciplina, não permitindo sua generalização a outros contextos ou a uma abordagem mais ampla, no nível do curso (ADRIAENSEN; BIJSMANS; GROEN, 2019; SANKARAN; MOHANTY, 2018; LUTSENKO, 2018; RUGE; MCCORMACK, 2017; SANTOS, 2017).

Alguns pesquisadores apontam como limitações das pesquisas realizadas o viés dos avaliadores. Isso ocorre não só com o uso de instrumentos de autoavaliação, como também na avaliação por pares e até na avaliação por professores, o que leva a um peso 
desproporcional nos resultados das avaliações em função de características pessoais e do envolvimento com os estudantes e com as atividades em avaliação (CANELAS; HILL; NOVICKI, 2017; MOTAHHARI-NEJAD, 2019; ABDULLAH et al., 2013; GILL; RITZHAUPT, 2013).

Neste contexto, o objetivo desta investigação foi testar os instrumentos para autoavaliação e avaliação pelos pares de competências transversais de estudantes que são parte integrante de um modelo em desenvolvimento na pesquisa de doutorado da primeira autora. Serão apresentados o processo de desenvolvimento dos itens do questionário, bem como os resultados da avaliação destes itens e das condições de aplicação por um grupo focal de especialistas e por um grupo focal com estudantes, envolvendo a autoavaliação e a avaliação pelos pares (colegas de equipe). O modelo prevê ainda a avaliação por professores e por agentes externos, etapas não contempladas nessa publicação. Parte-se da hipótese de que é possível avaliar as competências transversais dos estudantes de engenharia e sua aderência ao perfil profissional esperado, associando a avaliação por múltiplos agentes.

Entende-se que as competências transversais são desenvolvidas não só em disciplinas ou atividades acadêmicas, como também em contextos externos à formação universitária (CLARES; MORGA, 2019; GONZÁLEZ; WAGENAAR, 2003). Porém, a avaliação de competências precisa ser feita a partir da sua mobilização no contexto educacional em situações próximas a situações reais (ZABALA; ARNAU, 2015; CRAWLEY, 2014). Acredita-se ainda que uma maior quantidade de agentes avaliadores e observações ao longo do processo formativo, reduz os vieses e leva a uma avaliação mais confiável (CRAWLEY et al., 2014). A seguir, são apresentados o método utilizado para o desenvolvimento da pesquisa e os resultados dos grupos focais de especialistas e de estudantes.

\section{MÉTODO}

O desenvolvimento do método e dos instrumentos para avaliação de competências transversais de estudantes de engenharia utilizou como referência os procedimentos para construção e validação de instrumentos psicológicos, conforme proposto por Borsa e Seize (2017) e esquematicamente representado na Figura 1. 
Figura 1 - Etapas de desenvolvimento de instrumentos psicológicos

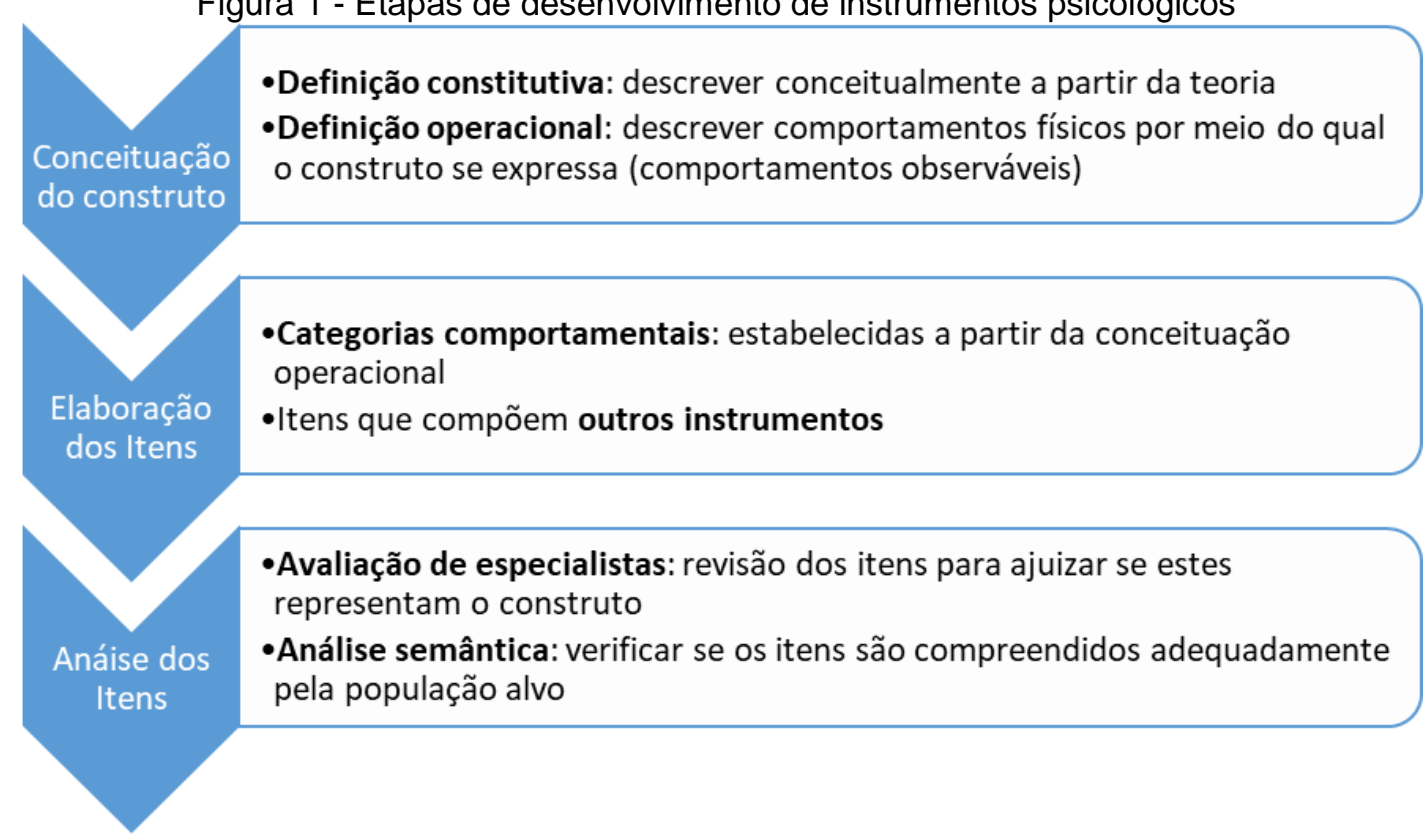

Fonte: autoria própria, a partir Borsa e Seize (2017).

Para conceituação do construto "competências transversais" foi realizada uma busca exploratória por artigos na base de periódicos da CAPES (Coordenação de Aperfeiçoamento de Pessoal de Nível Superior). As competências transversais a avaliar foram selecionadas a partir da revisão sistemática de literatura e das competências estabelecidas para o perfil do egresso dos cursos de engenharia da instituição de ensino onde a pesquisa foi realizada. Esta adotou como base a estrutura do CDIO syllabus (CRAWLEY et al., 2014). Foram, então, descritos comportamentos observáveis que representassem as competências que se desejava avaliar (categorias comportamentais) tomando-se como referências instrumentos utilizados por outros autores, constituindo, assim, os itens dos questionários de avaliação de competências transversais. Estes instrumentos, bem como o contexto de sua aplicação foram submetidos, então, a análise semântica e do contexto de aplicação por meio de um grupo focal de especialistas da área.

A pesquisa piloto com o grupo focal de estudantes foi realizada com uma turma de alunos de um curso de Engenharia de uma IES privada. Escolheu-se uma turma da disciplina "Desafio da Engenharia", que acontece regularmente no primeiro período letivo do curso. Nesta disciplina, os alunos desenvolvem em equipes um projeto relacionado à especialidade da engenharia que escolheram cursar. Optou-se por aplicar a pesquisa a um grupo de alunos ingressantes no curso em função do modelo de formação adotado pela IES e da possibilidade de continuidade longitudinal da pesquisa com este mesmo grupo nos períodos subsequentes. A turma era composta por 25 estudantes, distribuídos em 7 (sete) equipes de 2 (dois) a 5 (cinco) integrantes. Do total, 7 estudantes de quatro equipes responderam efetivamente à pesquisa. Cabe destacar que o modelo de avaliação não prevê a atribuição de nota.

\section{RESULTADOS}

Os itens a seguir detalham os resultados das avaliações realizadas pelo grupo focal de especialistas e os resultados obtidos nas autoavaliações e avaliações pelos pares com o grupo focal com estudantes. 


\subsection{GRUPO FOCAL DE ESPECIALISTAS}

O grupo focal de especialistas foi constituído por 7 (sete) integrantes, dentre coordenadores de curso, coordenadores pedagógicos e gestores da IES onde a pesquisa foi aplicada. Após uma reunião inicial para apresentar o objetivo da pesquisa e esclarecer possíveis dúvidas, foi encaminhado por meio de um formulário em Excel os itens contendo 40 comportamentos observáveis que representavam as competências transversais previstas no perfil do egresso dos cursos de Engenharia da IES. Para cada comportamento observável, os especialistas foram solicitados a responder a três questões. A primeira questão, visava a avaliar se cada item estava descrito claramente e de forma adequada ao contexto dos estudantes de engenharia. A segunda e a terceira questões visavam avaliar se os comportamentos ali descritos poderiam ser observados pelos professores e pelos colegas de equipe durante o desenvolvimento de trabalhos em equipe. Para cada questão, em cada item, era solicitada uma justificativa em caso de resposta negativa ou parcialmente satisfatória. Uma questão aberta procurava identificar se haveriam outras competências transversais a considerar no instrumento e foi incluído um espaço para comentários que os especialistas considerassem pertinentes ao desenvolvimento da pesquisa. A Tabela 1 apresenta um resumo das avaliações das questões pelos especialistas.

Tabela 1 - Consolidação das respostas às questões pelos especialistas

\begin{tabular}{c|c|c|c}
\hline Critério & $\begin{array}{c}\text { Questão 1 } \\
\text { Clareza dos } \\
\text { itens }\end{array}$ & $\begin{array}{c}\text { Questão 2 } \\
\text { Capacidade de } \\
\text { observação } \\
\text { pelos pares }\end{array}$ & $\begin{array}{c}\text { Questão 3 } \\
\text { Capacidade de } \\
\text { observação } \\
\text { pelo professor }\end{array}$ \\
\hline $\begin{array}{c}\text { Itens com respostas "sim" } \\
\text { de todos os especialistas }\end{array}$ & 30 & 16 & 2 \\
\hline $\begin{array}{c}\text { Itens com uma resposta } \\
\text { "não" ou "talvez" }\end{array}$ & 6 & 13 & 12 \\
\hline $\begin{array}{c}\text { Itens com duas respostas } \\
\text { "não" ou "talvez" }\end{array}$ & 2 & 6 & 19 \\
\hline $\begin{array}{c}\text { Itens com mais de 2 } \\
\text { respostas "não" ou "talvez" }\end{array}$ & 2 & 5 & 7 \\
\hline TOTAL & $\mathbf{4 0}$ & $\mathbf{4 0}$ & $\mathbf{4 0}$ \\
\hline
\end{tabular}

Fonte: elaboração própria.

Quanto à questão 1 (um), referente à clareza da descrição dos comportamentos observáveis, os especialistas foram unânimes em considerar que 30 itens estavam claramente descritos. Para cada um dos outros 10 (dez) itens, todas as observações do grupo foram analisadas e as descrições dos comportamentos revisadas visando deixa-las mais claras. No geral, os ajustes consistiram na substituição de termos julgados de difícil compreensão, na complementação da descrição dos itens ou na exclusão de termos para focar em uma competência específica.

Com relação à possibilidade de os alunos avaliarem os comportamentos durante os trabalhos em equipe (questão 2), para 16 itens, os especialistas foram unânimes em considerar que os alunos seriam capazes de observar aquele comportamento e em 13 itens apenas um dos sete especialistas considerou que os alunos poderiam ter dificuldade em observar (Tabela 1). Destes 13, em apenas um, referente à realização de testes e experimentos, foi pontuada a resposta "não"; nos demais, os especialistas pontuaram como "talvez". Considerando que a pandemia da COVID-19 impôs a necessidade de migrar as atividades de ensino para o modelo remoto no primeiro semestre de 2020.1 quando a pesquisa piloto foi realizada, os pesquisadores decidiram pela exclusão deste item do questionário, visto a dificuldade de realização de experimentos neste cenário. 
Em 11 itens, dois ou mais componentes do grupo focal pontuaram que os alunos poderiam não conseguir avaliar os colegas de equipe (Tabela 1). Considerando a percepção dos especialistas de que o formulário continha muitos itens a avaliar, podendo gerar uma resistência dos alunos a preenchê-lo, após análise dos pesquisadores, foram excluídos 9 dos 11 itens pontuados por dois ou mais especialistas como de difícil avaliação pelos alunos. Dois itens foram mantidos no questionário. São eles: pensamento crítico e comunicação escrita. Considerando as justificativas apresentadas pelo grupo focal e a importância destas competências para a pesquisa e para a formação do engenheiro, os pesquisadores decidiram pela sua manutenção. Como os instrumentos ainda seriam aplicados a um grupo focal de estudantes, caso necessário, estes itens poderiam ser ajustados ou até excluídos posteriormente.

Com relação aos professores (questão 3), no geral, os especialistas relataram que estes teriam maior dificuldade de observar os comportamentos relacionados. Em apenas dois itens o grupo focal foi unânime em pontuar que os professores seriam capazes de avaliar o comportamento dos alunos e em 26 itens, dois ou mais especialistas avaliaram que os professores poderiam ter dificuldade de observar os comportamentos. Destes, 24 comportamentos foram excluídos da versão final do questionário de avaliação para os professores. Os dois itens mantidos referiam-se a criatividade e pontualidade. $O$ item que avalia a criatividade foi mantido por se entender a importância da criatividade enquanto competência transversal dos estudantes de engenharia e que esta poderia ser avaliada a partir das soluções apontadas pelos grupos aos desafios propostos. $O$ item pontualidade foi mantido por se entender que este poderia ser avaliado a partir do cumprimento dos prazos de entrega pelos grupos e pela participação no horário das atividades planejadas para acompanhamento do desenvolvimento dos projetos.

Os especialistas pontuaram ainda algumas questões relevantes a serem consideradas na pesquisa. Três deles comentaram sobre a grande quantidade de itens a avaliar, o que poderia levar a um desestímulo por parte dos estudantes para o preenchimento do questionário. Foi pontuada também que, a avaliação de muitos comportamentos por parte dos docentes seria possível, mas exigiria uma participação ativa dos mesmos no processo de desenvolvimento dos projetos. Além disso, dois especialistas comentaram sobre a dificuldade de se ter uma percepção individual de cada aluno quando as turmas são grandes, exigindo mais tempo de interação e observação por parte do docente, tendo sido sugerido por um deles que o professor avaliasse o grupo como um todo e não cada componente individualmente. Três componentes do grupo levantaram ainda competências adicionais que poderiam ser incluídas no questionário, a exemplo da capacidade de fazer perguntas e de lidar com pressão. Porém, ponderando que as competências sugeridas foram diferentes entre eles e levando em conta as considerações sobre o tamanho do questionário, já salientadas acima, decidiu-se por não incluir itens no instrumento. Assim, a versão final do questionário a ser aplicada aos alunos do grupo focal foi composta por 30 itens e do professor, por 16 itens.

\subsection{GRUPO FOCAL COM ESTUDANTES}

Os 7 (sete) estudantes que participaram da pesquisa são originários de colégios particulares, sendo que apenas um fez curso técnico previamente à graduação e 4 (quatro) já haviam cursado (não necessariamente concluído) outra graduação. Apesar da pesquisa ter sido aplicada em uma disciplina prevista na grade regular para o primeiro semestre do curso, um dos estudantes ingressou no curso em 2018, 4 (quatro) ingressaram em 2019 e apenas 2 (dois) em 2020. Nenhum deles havia estagiado ou participado de iniciação científica, quando da aplicação da pesquisa, e apenas 2 já haviam exercido algum trabalho 
remunerado por menos de 6 meses. Destaca-se, no entanto, o envolvimento dos estudantes com as iniciativas estudantis da instituição, já que 5 (cinco) deles participam ou já participaram da empresa júnior e um da atlética (grupo de alunos que se dedica a promoção e participação em atividades e competições esportivas). Cabe comentar aqui que dos 7 (sete) participantes, 2 (dois) são do sexo masculino e 5 (cinco) do sexo feminino, o que representa uma taxa de respondentes de $50 \%$ entre as mulheres e de $13,3 \%$ entre os homens já que, do total da turma, 10 alunos eram do sexo feminino e 15 do sexo masculino.

Para cada comportamento descrito, os estudantes deveriam responder o quanto, na percepção deles, o aluno avaliado (incluindo o próprio estudante na autoavaliação) demonstrava ter aquela capacidade desenvolvida, conforme escala tipo Likert de 5 (cinco) pontos: sendo 1 - Quase nada desenvolvida, 2 - Pouco desenvolvida, 3 - Moderadamente desenvolvida, 4 - Bem desenvolvida e 5 - Muito bem desenvolvida. Era possível também atribuir a resposta 0 - Não observado no período, permitindo aos participantes pontuar quais comportamentos eles não puderam observar no semestre. O questionário continha, além das questões especificas para avaliação dos comportamentos observáveis, duas questões abertas, uma sobre a quantidade de itens e o tempo para reposta ao questionário e outra sobre o grau de dificuldade em avaliar os comportamentos dos colegas.

Em função do isolamento social imposto pela pandemia da COVID-19, algumas atividades, previstas inicialmente para serem realizadas de forma presencial, foram adaptadas para aplicação de forma remota. Os dados de autoavaliação dos estudantes e avaliação dos pares foram coletados por meio de uma planilha disponibilizada em uma sala de aula virtual, garantindo a confidencialidade dos dados, só acessados pela pesquisadora responsável. Para cada grupo e para cada aluno, foi estabelecido um código, de forma a que não se pudesse identificá-los posteriormente. Os dados coletados foram, então, consolidados em uma planilha única, sendo determinadas as medianas para cada comportamento observado.

No que se refere à quantidade de questões e ao tempo para respondê-las, a maioria dos alunos (cinco) entendeu que o esforço estava adequado ao objetivo da pesquisa. Dois alunos acharam grande a quantidade de questões. Estes, participaram de grupos com 4 (quatro) e 5 (cinco) integrantes, o que amplia o esforço para avaliação dos pares. Com relação ao grau de dificuldade para observar as competências dos colegas, dos 7 (sete) respondentes, 3 (três) não relataram dificuldades, sendo que um deles destacou que a observação dos comportamentos foi facilitada por já terem trabalhado no mesmo grupo no ano anterior. Um dos alunos destacou que o fato de o trabalho ter sido desenvolvido remotamente dificultou a observação das competências avaliadas. Um aluno pontuou, ainda, que nem todas as competências foram necessárias ao trabalho em equipe, dificultando a observação de alguns comportamentos. Por fim, um dos alunos apontou ser complexo avaliar outras pessoas em função dos diversos fatores que podem influenciar nos comportamentos como "problemas pessoais, momento da vida e coisas adversas", sendo difícil encontrar um equilíbrio.

Foram recebidas ao todo 25 avaliações, sendo sete autoavaliações e 18 avaliações dos pares, totalizando 750 itens respondidos. A Tabela 2 apresenta a quantidade de itens que os estudantes entenderam não ser possível observar no período e a quantidade de comportamentos observados, registrados na avaliação na escala de 1 (um) a 5 (cinco). As respostas "0 - Não observado no período" foram dadas principalmente por um único aluno que pontuou em 70 itens ( 6 na autoavaliação e 64 na avaliação dos pares) que não poderia observar. Além disso, outro estudante pontuou em 29 das 30 questões na avaliação de um colega específico que o comportamento não foi observado no período, indicando que, possivelmente, este colega não tenha participado efetivamente do desenvolvimento do 
trabalho. Isso totaliza 99 das 107 avaliações registradas como "0 - Não observado no período", o que indica que a grande maioria dos comportamentos puderam ser observados. Em 16 das 25 avaliações recebidas, os alunos entenderam ser possível observar todos os comportamentos listados, indicando uma boa aderência dos comportamentos ao trabalho em equipe desenvolvido no contexto da educação em engenharia.

Tabela 2 - Quantidade de itens observados e não observados nas avaliações por pares e nas autoavaliações.

\begin{tabular}{l|l|l|l|l}
\hline \multirow{2}{*}{ Respostas } & Avaliação dos Pares & \multicolumn{2}{l}{ Autoavaliação } \\
\cline { 2 - 5 } & Quant. & $\%$ & Quant. & $\%$ \\
\hline 0 - Não observado no período & 100 & $19 \%$ & 7 & $3 \%$ \\
\hline $\begin{array}{l}\text { Possível observar (Escala Likert de 1 a } \\
\text { 5) }\end{array}$ & 440 & $81 \%$ & 203 & $97 \%$ \\
\hline TOTAL & 540 & $100 \%$ & 210 & $100 \%$ \\
\hline
\end{tabular}

Fonte: elaboração própria.

Curiosamente, o item que recebeu o maior número de respostas "0 - Não observado no período", com 7 (sete) avaliações, foi "elaboração de material de suporte a apresentações". Uma possível justificativa para isso é a possibilidade de que os alunos tenham concentrado este trabalho em um dos membros da equipe, não permitindo avaliar essa competência dos demais membros. Na sequência, com 6 indicações de não ter sido possível avaliar, apareceram os itens referentes a: colaboração com o grupo, estímulo à colaboração e reconhecimento de contribuições, suporte aos membros do grupo, monitoramento de resultados e feedback, habilidade de evitar conflitos, mediação de conflitos e reconhecimento do próprio erro. Algumas hipóteses podem ser levantadas para a maior dificuldade de observação destes itens no período como o fato de parte destes comportamentos estarem associados à atuação no papel de líder, sendo difícil de observar nos colegas que não estavam nesse papel. Ainda, há a possibilidade de, em algumas equipes, não terem havido conflitos ou falhas explícitas durante a execução do projeto. Não se pode descartar que o desenvolvimento dos trabalhos de forma remota pode também ter levado à dificuldade de observação de alguns comportamentos, como foi relatado por um dos estudantes.

O Gráfico 1 apresenta o resumo do percentual de respostas por nível da escala Likert, tanto na avaliação por pares quanto na autoavaliação. Observa-se uma maior quantidade de respostas 1 (um) e 2 (dois) recebida pelos pares (7\%) quando comparado ao percentual de respostas da autoavaliação para estes mesmos níveis (3\%). No extremo oposto da escala, os itens 4 e 5 receberam somados $71 \%$ das respostas nas avaliações dos pares, enquanto receberam $73 \%$ de respostas nas autoavaliações. 
Comparativo do Percentual de Respostas por Nível da Escala Likert

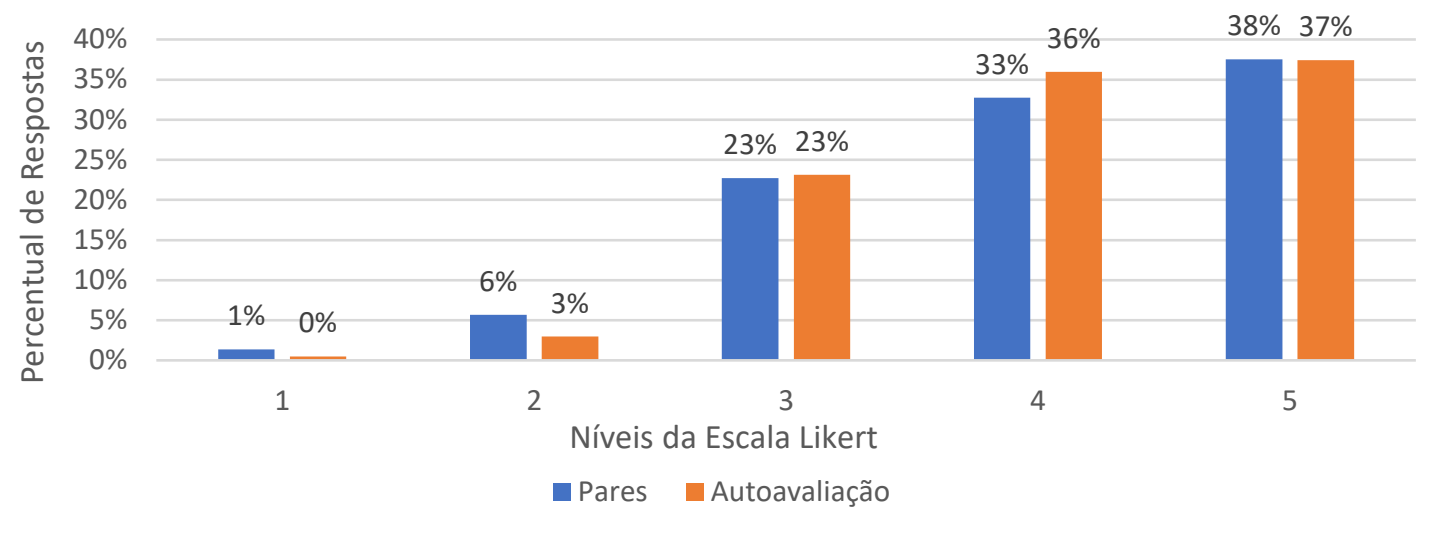

Fonte: elaboração própria.

Percebe-se que a grande maioria das respostas esteve nos níveis 4 e 5 da escala Likert, indicando que os estudantes se autoavaliam e avaliam que os colegas apresentam os comportamentos associados às competências transversais bem desenvolvidos ou muito bem desenvolvidos, apesar de estarem ainda no início de sua formação.

A Tabela 8 a seguir apresenta a mediana das respostas considerando as autoavaliações, as avaliações por pares e o geral (conjunto total das avaliações). Para cálculo da mediana foram excluídas as respostas "0 - Não observado no período". Os comportamentos observáveis foram aqui representados de forma resumida, para facilitar a exposição e compreensão dos dados.

É possível observar que, para a grande maioria dos comportamentos (22 dos 30 itens avaliados), a mediana geral foi 4,0, indicando uma percepção dos alunos de que estas competências estão "bem desenvolvidas". Em cinco itens, observa-se uma mediana 5,0 indicando que os alunos avaliam ter essas capacidades muito bem desenvolvidas. Estes cinco itens (respeito às diferenças, ética e profissionalismo, elaboração de material de suporte a apresentações, domínio de tecnologias para comunicação, aceitação a críticas e feedback) apresentam mediana 5,0 tanto nas autoavaliações quanto nas avaliações por pares. Em três itens (identificação de problemas, criatividade, determinação para conclusão da tarefa), observa-se a mediana 3,0 , ou seja, competências moderadamente desenvolvidas. Este resultado, mesmo que preliminar, indica competências em que a instituição de ensino deve envidar esforços para melhor capacitar os estudantes. É interessante notar, no entanto, que o item "criatividade" apesar de apresentar uma mediana 3,0 na avaliação por pares (assim como no geral) apresenta mediana 4,0 na autoavaliação.

Em apenas 7 (sete) itens, a mediana da avaliação por pares apresenta resultado diferente da autoavaliação. Em quatro deles, a autoavaliação apresenta resultados maiores do que a avaliação por pares (formulação e defesa de hipóteses, criatividade, habilidade de evitar conflitos, mediação de conflitos). Já em outros três, a autoavaliação apresenta menores medianas do que a avaliação por pares (adaptabilidade a um novo papel, estímulo à colaboração e reconhecimento de contribuições, solidariedade aos membros do grupo). De uma forma geral, portanto, os resultados das autoavaliações e das avaliações por pares foi muito semelhante, não indicando, a princípio, uma tendência significativa a que os alunos se autoavaliem melhor do que avaliem os pares ou vice-versa. 
Tabela 3 - Mediana das Autoavaliações, das Avaliações por Pares e Geral por Item Avaliado Comportamentos Observáveis (Resumido)

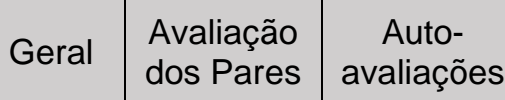

\begin{tabular}{|c|c|c|c|}
\hline Identificação de problemas & 3,0 & 3,0 & 3,0 \\
\hline Formulação e defesa de hipóteses & 4,0 & 3,5 & 4,0 \\
\hline Realização de pesquisas & 4,0 & 4,0 & 4,0 \\
\hline Pensamento sistêmico & 4,0 & 4,0 & 4,0 \\
\hline Pensamento crítico & 4,0 & 4,0 & 4,0 \\
\hline Criatividade & 3,0 & 3,0 & 4,0 \\
\hline Determinação para conclusão da tarefa & 3,0 & 3,0 & 3,0 \\
\hline Resistência à pressão em caso de falhas & 4,0 & 4,0 & 4,0 \\
\hline Adaptabilidade a um novo papel & 4,0 & 4,0 & 3,5 \\
\hline Aprendizagem autônoma & 4,0 & 4,0 & 4,0 \\
\hline Orientação a outros membros do grupo & 4,0 & 4,0 & 4,0 \\
\hline Proatividade & 4,0 & 4,0 & 4,0 \\
\hline Pontualidade & 4,0 & 4,0 & 4,0 \\
\hline Planejamento e controle de recursos & 4,0 & 4,0 & 4,0 \\
\hline Respeito às diferenças & 5,0 & 5,0 & 5,0 \\
\hline Ética e profissionalismo & 5,0 & 5,0 & 5,0 \\
\hline Colaboração com o grupo & 4,0 & 4,0 & 4,0 \\
\hline Estímulo à colaboração e reconhecimento de contribuições & 4,0 & 5,0 & 4,0 \\
\hline Solidariedade aos membros do grupo & 4,0 & 4,5 & 4,0 \\
\hline Monitoramento de resultados e oferte de feedback & 4,0 & 4,0 & 4,0 \\
\hline Comunicação oral em pequenos grupos & 4,0 & 4,0 & 4,0 \\
\hline Escuta ativa & 4,0 & 4,0 & 4,0 \\
\hline Comunicação escrita & 4,0 & 4,0 & 4,0 \\
\hline Elaboração de material de suporte a apresentações & 5,0 & 5,0 & 5,0 \\
\hline Comunicação oral em público & 4,0 & 4,0 & 4,0 \\
\hline Domínio de tecnologias para comunicação & 5,0 & 5,0 & 5,0 \\
\hline Habilidade de evitar conflitos & 4,0 & 4,0 & 4,5 \\
\hline Mediação de conflitos & 4,0 & 4,0 & 4,5 \\
\hline Reconhecimento do próprio erro & 4,0 & 4,0 & 4,0 \\
\hline Aceitação a críticas e feedback & 5,0 & 5,0 & 5,0 \\
\hline
\end{tabular}

Fonte: elaboração própria.

\section{CONSIDERAÇÕES FINAIS}

Avaliar competências, em especial, competências transversais, é um novo desafio para os professores e para as instituições de ensino de engenharia. Este artigo apresentou resultados parciais de um estudo que está sendo conduzido, visando a proposição de um modelo de avaliação de competências transversais que possa ser aplicado de forma longitudinal, ao longo do percurso formativo dos estudantes. Para reduzir os efeitos dos 
vieses dos avaliadores, o modelo conceitual prevê a avaliação por múltiplos agentes, incluindo, além da autoavaliação, as avaliações pelos pares, pelos professores e por agentes externos. Cabe salientar que o modelo não prevê que as avaliações sejam utilizadas para atribuição de notas e, sim, como ferramenta para promover a melhoria contínua e o aprendizado autônomo dos estudantes. É importante comentar também que se trata de um estudo preliminar, com um grupo pequeno de estudantes, não permitindo a generalização dos resultados parciais encontrados.

A análise do grupo focal de especialistas permitiu identificar que muitos comportamentos associados às competências transversais são mais fáceis de avaliar pelos próprios estudantes durante o desenvolvimento de trabalhos em equipe, do que pelos professores, indicando que o método proposto pode ser interessante para complementa 0 sistema de avaliação das instituições. Ainda, foi salientado que uma participação ativa dos professores na orientação dos projetos pode facilitar a observação dos comportamentos.

O estudo o grupo focal de estudantes envolvendo autoavaliação e avaliação dos pares permitiu perceber que, no geral, o instrumento foi bem aceito pelos estudantes, sendo possível avaliar a grande maioria dos itens propostos. Apesar da pequena amostra, foi possível notar indicações de que o questionário se mostrou grande para os grupos maiores (em função da quantidade de colegas a avaliar) e que uma maior maturidade e convivência com o grupo (inclusive de forma presencial) pode ajudar nas avaliações. Não se percebeu diferenças significativas entre as autoavaliações e avaliações pelos pares. Observou-se ainda que, mesmo no início do curso, os estudantes consideram que já possuem boa parte das competências avaliadas bem ou muito bem desenvolvidas.

A evolução da pesquisa prevê o refinamento dos itens com base nas estratégias adotadas para desenvolvimentos de instrumentos psicológicos e no aprofundamento dos grupos focais com a participação de estudantes e professores. Além disso, a pesquisa deverá ser aplicada a um número maior de estudantes e serão realizadas análises estatísticas apropriadas para validação do modelo proposto. Acredita-se que, ao explicitar as competências transversais e avaliar em que grau os estudantes estão evoluindo no desenvolvimento destas competências, favorece-se o reconhecimento dos gaps e a busca pela melhoria contínua, não só por parte dos estudantes, como também por parte dos professores e das instituições de ensino.

\section{REFERÊNCIAS}

ABDULLAH, S. R. S. et al. A comparative analysis between direct and indirect measurement of year I integrated project. International Education Studies, v. 6, n. 6, p. 143-150, 2013.

ADRIAENSEN, J.; BIJSMANS, P.; GROEN, A. Monitoring generic skills development in a bachelor European studies. Journal of Contemporary European Research, v. 15, n. 1, p. 110-127, 2019.

AGUADO, David et al. Evaluación de competencias transversales en universitarios.

Propiedades psicométricas iniciales del Cuestionario de Competencias

Transversales. REICE. Revista Iberoamericana sobre Calidad, Eficacia y Cambio en

Educación, v. 15, n. 2, p. 129-152, 2017.

BALDERAS, A. et al. Learning management systems activity records for students' assessment of generic skills. IEEE Access, v. 6, p. 15958-15968, 2018. 
BORSA, J. C.; SEIZE, M. M. Construção e adaptação de instrumentos psicológicos: dois caminhos possíveis. In: DAMÁSIO, B. F.; BORSA, J. C. (Org.). Manual de desenvolvimento de instrumentos psicológicos. São Paulo: Vetor, 2017. p. 15-37.

BRIDGES, David. Transferable skills: a philosophical perspective. Studies in Higher Education, v. 18, n. 1, p. 43-51, 1993.

CANELAS, D. A.; HILL, J. L.; NOVICKI, A. Cooperative learning in organic chemistry increases student assessment of learning gains in key transferable skills. Chemistry Education Research and Practice, v. 18, n. 3, p. 441-456, 2017.

CLARES, P. M.; MORGA, N. G. El dominio de competencias transversales en Educación Superior en diferentes contextos formativos. Educação e Pesquisa, v. 45, 2019.

CRAWLEY, E. et al. Rethinking engineering education: the CDIO approach. $2^{a}$ ed. Editora Springer, 2014.

FLEURY, M. T. L.; FLEURY, A. Construindo o Conceito de Competência. Revista de Administração Contemporânea, v. 5, p. 183-196, 2001.

GILL, G.; RITZHAUPT, A. Systematically evaluating the effectiveness of an information systems capstone course: implications for practice. Journal of Information Technology Education: Research, v. 12, n. 1, p. 69-94, 2013.

GONZÁLEZ, J.; WAGENAAR, R. Tuning educational structures in Europe: final report pilot project-phase 1. University of Deusto, Bilbao, 2003, p. 59-98.

LUTSENKO, G. Case study of a problem-based learning course of project management for senior engineering students. European Journal of Engineering Education, v. 43, $n$. 6, p. 895-910, 2018.

MORENO, M. L. R. De la evaluación a la formación de competencias genéricas: aproximación a un modelo. Revista Brasileira de Orientação Profissional, v.7, n.2, p. 33-48, 2006.

MORGA, N. G.; CUSÓ, J. P.; MARTÍNEZ JUÁREZ, M. Desarrollo de Competencias Transversales en la Universidad de Murcia: Fortalezas, Debilidades y Propuestas de Mejora. Revista Digital de Investigación en Docencia Universitaria, v. 12, n. 2, p. 88113, 2018.

MOTAHHARI-NEJAD, $\mathrm{H}$. Professional competencies in engineering: examining validity and measurement invariance of a scale. Studies in Higher Education, p. 1-12, 2019.

ROCHA, Magda. Predictors of the acquisition and portability of transferable skills: a longitudinal Portuguese case study on education. Higher Education, v. 69, n. 4, p. 607624, 2015.

RUGE, G.; MCCORMACK, C. Building and construction students' skills development for employability-reframing assessment for learning in discipline-specific contexts.

Architectural Engineering and Design Management, v. 13, n. 5, p. 365-383, 2017. 
SANKARAN, M.; MOHANTY, S. Student perception on achieved graduate attributes and learning experiences: a study on undergraduate engineering students of India.

International Journal of Continuing Engineering Education and Life-Long Learning, v. 28 , n. 1, p. 77-98, 2018.

SANTOS, S. C. PBL-SEE: an authentic assessment model for PBL-based software engineering education. IEEE Transactions on Education, v. 60, n. 2, p. 120-126, 2017.

YE-LIN, Yiyao et al. Diseño, aplicación y valoración de actividades destinadas al trabajo y evaluación de múltiples competencias transversales en grupos numerosos de máster en ingeniería, empleando el aprendizaje basado en proyectos. Educatio Siglo XXI, v. 37, n. 3 Nov-Feb, p. 133-162, 2019.

ZABALA, A.; ARNAU, L. Como aprender e ensinar competências. Porto Alegre: Penso Editora, 2014.

\title{
SELF-ASSESSMENT AND ASSESSMENT BY PEERS OF ENGINEERING STUDENTS TRANSFERABLE SKILLS: A PILOT STUDY
}

\begin{abstract}
The recent changes in the expected leaning outcomes of engineering students in order to meet the transformations of contemporary society imposes professors and higher education institutions the challenge not only of training, but also of assessing students transferable skills. The assessment of these skills is a complex process, not yet sufficiently studied by researchers; therefore, it lacks the development of appropriate tools. This work presents the partial results of a doctoral study, aiming at proposing a model for assessing students' transferable skills that considers self-assessment and peer assessment, as well as, the assessment by tutors and external agents, such as internship supervisors and clients. The preliminary results, considering self-assessment and peer assessment, indicate that the proposed model is adequate for its purpose, making it possible to involve students in the assessment of transferable skills. There were no significant differences between the medians of self and peer assessments. The next steps include the refinement of the instrument items and the application of the assessment instruments with a larger number of students, besides professors and external agents. The researchers believe that, by knowing the required transferable skills and assessing these skills, it is possible for the students, professors and higher education institutions to recognize the student's gaps and search for continuous improvement.
\end{abstract}

Keywords: Engineering Education. Transferable skills. Students' assessment. Selfassessment. Peer assessment. 